\title{
Gastronomi dalam Cerita Rakyat Ainu Jepang
}

\author{
Ida Ayu Laksmita Sari, I Nyoman Darma Putra, dan Ni Luh Kade Yuliani Giri \\ Fakultas Ilmu Budaya \\ Universitas Udayana \\ Jalan Pulau Nias No. 13 Denpasar - Bali, 80114 \\ Tlp.081916769609, E-mail: laksmita_sari@unud.ac.id
}

\begin{abstract}
This article analyzes the gastronomic aspects of the Ainu folklore in Japan. Gastronomic aspects examined include how Ainu folklore narrates how they collect and cook food materials, how they consume, and what cultural values are attached to both the process of food production and consumption. The study applied library research and the object of analysis were selectively chosen from Ainu Mukashi Banashi's book: Hitotsubu no Satchiporo (2012), an anthology of Ainu folklore edited by Kayano Shigeru. The stories chosen analyzed by the literary anthropology theory. The results show that the Ainu folklore contains narratives about how people collect food, cook, and consume them. The study of the gastronomic narratives of Ainu folklore presents a novelty that folklore not only contains a moral message for character formation but is also a medium for preserving and continuing food and culinary culture across time and generations.
\end{abstract}

Keywords: Ainu folktale, literary gastronomy, traditional food of Ainu Japan

\begin{abstract}
ABSTRAK
Artikel ini menganalisis aspek gastronomi dari cerita rakyat Ainu Jepang. Aspek gastronomi yang dikaji meliputi bagaimana cerita rakyat Ainu menceritakan cara mereka mengumpulkan dan memasak bahan makanan, bagaimana mereka mengonsumsi, dan nilai-nilai budaya apa yang melekat pada proses produksi dan konsumsi makanan. Penelitian dilakukan dengan riset perpustakaan dan objek kajian dipilih secara selektif dari buku Ainu Mukashi Banashi: Hitotsubu no Satchiporo (2012), sebuah antologi cerita rakyat Ainu dengan editor Kayano Shigeru. Data dianalisis dengan teori antropologi sastra. Hasil penelitian menunjukkan bahwa cerita rakyat Ainu mengandung narasi tentang cara masyarakat mengumpulkan bahan makanan, memasak, dan mengkonsumsinya. Studi tentang narasi gastronomi cerita rakyat Ainu menyajikan hal baru bahwa cerita rakyat tidak saja mengandung pesan moral untuk pembentukan karakter tetapi juga menjadi media untuk melestarikan dan meneruskan budaya makanan dan kuliner lintas waktu dan generasi.
\end{abstract}

Kata Kunci: cerita rakyat Ainu, gastronomi sastra, makanan tradisional Ainu Jepang

\section{PENDAHULUAN}

Cerita rakyatsering diidentikkan dengan warisan budaya yang mengandung nilai moral untuk memberikan nasehat. Padahal, cerita rakyat juga mengandung berbagai pengetahuan seperti sejarah, mitologi, sistem kepercayaan, dan mata pencaharian masyarakat (Danandjaja, 1995, hlm. 202-214; 1986, hlm. 3-4). Jika disimak secara kreatif, cerita rakyat juga mengandung cara-cara memasak makanan atau jenis makanan yang menjadi bagian hidup masyarakat, cara-cara mereka mengumpulkan bahan makanan dan mengolahnya untuk konsumsi, serta semangat 
masyarakat dalam melestarikan jenis-jenis makanan khas mereka. Keterampilan dan seni memasak, menyajikan, dan mengonsumsi makanan dikenal dengan istilah gastronomi (Hjalager dan Richards eds., 2002, hlm. 3). Karya sastra, termasuk cerita rakyat, yang mengandung informasi mengenai makanan dapat dimasukkan ke dalam sastra gastronomi.

Artikel ini mengkaji cerita rakyat Ainu Jepang khususnya yang mengandung narasi dan informasi mengenai makanan, termasuk tentang cara mengumpulkan bahan makanan, cara memasak, dan cara menikmati serta melestarikan budaya makanan Ainu Jepang. Kajian ini mengaplikasikan pendekatan gastronomi sastra. Gastronomi berasal dari bahasa Yunani Kuno, yaitu 'gastronomia'. Kata 'gastro' berarti perut atau lambung, sementara 'nomia' berarti aturan atau hukum. Gastronomi sastra merupakan penelitian interdisplin dengan perspektif memahami sastra yang berkaitan dengan makanan (Endraswara, 2018, hlm. 5).

Masyarakat Ainu merupakan penduduk asli Jepang yang secara historis dominan tinggal di Hokkaido dan dulunya menerapkan praktik hidup meramu dan berburu. Dalam cerita rakyat mereka tentang meramu dan berburu banyak dituturkan hal-hal yang berkaitan dengan makanan (Watson, Lewallen, dan Hudson, 2014, hlm. 1-24) dan nilai-nilai yang berkaitan dengan proses produksi dan konsumsi makanan, baik dalam konteks ritual maupun dalam konteks keluarga.

Nenek moyang masyarakat Ainu meneruskan nilai-nilai gastronomi mereka melalui cerita rakyat. Cerita rakyat yang memiliki dimensi gastronomi menampilkan ihwal makanan secara beragam, misalnya ada kisah yang sebatas menyebutkan nama makanan yang dikonsumsi tokoh cerita, ada yang menuturkan rinci cara-cara mengolah makanan, ada tradisi mengolah makanan bersama untuk ritual, dan ada juga cerita yang menjadikan makanan sebagai media untuk menyampaikan nilai-nilai sosial budaya dan sistem kepercayaan.

Sehubungan dengan persoalan di atas, artikel ini mengkaji bagaimana cerita rakyat Ainu menarasikan cara masyarakat mengumpulkan bahan dan mengolah bahan makanan dan bagaimana proses pengolahan dan pola konsumsi makanan dikaitkan dengan nilai budaya dan sistem kepercayaan mereka.

Urgensi dari penelitian ini terletak pada tiga hal yang saling berkaitan. Pertama, kajian gastronomi sastra dalam cerita rakyat belum banyak dilakukan para ahli, mengingat kajian atas cerita rakyat kebanyakan diarahkan untuk mengangkat nilai-nilai moral cerita. Kedua, kajian ini diharapkan memberikan kontribusi dalam pendekatan gastronomi sastra dan dalam mengangkat sistem produksi dan konsumsi serta nilai budaya yang terkait dengan budaya gastronomi masyarakat Ainu. Ketiga, memproduksi dan mengonsumi makanan menjadi gaya hidup baru dan sumber identitas masyarakat postmodern (Hjalager dan Richards eds., 2002, hlm. 3). Kontribusi teoritis dan praktis dalam kajian ini diharapkan saling mendukung.

Kajian ini diharapkan dapat memperkenalkan cerita rakyat Ainu dari Jepang. Selama ini, budaya Jepang yang 
banyak dikenal di Indonesia adalah anime, manga, dan cosplay (Setiawan, Haryono, dan Burhan, 2014, hlm. 39-48). Kajian kaitan sastra dan gastronomi belakangan mulai berkembang di Indonesia dengan mengkaji sastra Indonesia (Bramantio, 2013, hlm. 4155). Artikel ini mengkaji sastra lisan berupa cerita rakyat Ainu. Aspek kuliner bisa dikaji dari berbagai segi, seperti aspek industri kreatif termasuk desain kemasan (Pialang dan Darmawan, 2014, hlm. 285-294).

Dalam konteks kajian Jepang, sarjana yang meneliti kuliner negeri ini semakin banyak. Hayashi (1970) mengkaji makanan masyarakat Ainu khususnya dalam konteks pertanian dan tanaman liar dengan menggunakan cerita rakyat sebagai sumber data dan kajian. Malina et. al (2016), an Vecco (20010), Barrère et. al (2012) meneliti gastronomi sebagai heritage yang perlu dilestarikan, tak hanya sebagai produk, tapi juga aspek tata cara dalam makan dan minum.

Yang menarik juga kajian Bestor dan Besto (2011) bagi Jepang makanan tak hanya sumber ekonomi dan identitas, tetapi juga media untuk ekspresikan soft power, yaitu memperkenalkan budaya bangsa kepada masyarakat internasional. Indikator keberhasilannya adalah kehadiran masakan Jepang di berbagai tempat di dunia dan juga setiap wisatawan yang datang ke Jepang untuk mencoba makanan Jepang.

Artikel ini memiliki kemiripan dengan kajian Hayashi (1970) karena sama-sama menganalisis cerita rakyat Ainu, namun perbedaannya adalah artikel ini menganalisis aspek kuliner lebih terfokus pada proses pencarian bahan, memasak, dan cara mengonsumsi.

\section{METODE}

Data dikumpulkan lewat studi kepustakaan yaitu dengan membaca cerita rakyat Ainu dan secara selektif memilih kisah-kisah yang bertema atau bersubtema tentang makanan atau bahan-bahan lain yang berkaitan dengan bahan makanan, cara mengolah, cara mengonsumsi, dan makanan yang berkaitan dengan mata pencaharian dan budaya. Data cerita penelitian ini adalah materi utama berupa teks antologi cerita rakyat Ainu Jepang Ainu Mukashi Banashi: Hitotsubu no Sacchiporo (2012) yang disunting oleh Kayano Shigeru.

Data dikaji dengan kombinasi dua pendekatan yaitu gastronomi sastra dan teori antropologi sastra. Pertama, melihat dimensi makanan dari teks sastra, sedangkan yang kedua membantu memahami nilai budaya makanan masyarakat Ainu. Data yang sudah terkumpul dikelompokkan dan dimasukkan ke dalam tabel untuk acuan analisis yang sistematis.

Masyarakat Ainu Jepang termasuk indigenous people (etnik pribumi) yang banyak mendapat perhatian dari kalangan peneliti. Hal ini terbukti dari publikasi-publikasi tentang eksistensi masyarakat dan budaya. Seperti juga berlaku pada umumnya untuk penelitian masyarakat minoritas yang dianggap memiliki kebudayaan yang unik, penelitian-penelitian tentang Ainu pun pada awalnya banyak dilakukan kalangan 
antropologi dengan fokus keunikan budaya dan masyarakat Ainu.

Kajian-kajian antropologi diikuti dan dilanjutkan oleh kajian dengan disiplin lainnya seperti bahasa, sejarah, sastra lisan (tradisi lisan), kajian budaya (identitas), gender, arsitektur, dan pariwisata. Dari penelitian tersebut, belum ada yang memberikan perhatian pada aspek gastronomi atau tata boga dari cerita rakyat yang ada, padahal aspek tersebut sangat menarik dan muncul berulang dalam cerita rakyat Ainu. Manusia dalam cerita rakyat bukan saja hidup dan bekerja atau bermain, tetapi juga dilukiskan mencari dan memasak makanan. Lewat makanan itu interaksi antara tokoh cerita bisa disimak dan diberikan makna.

Bukti kajian antropologi yang mengawali penelitian tentang masyarakat Ainu bisa dilihat dari buku Beyond Ainu Studies (Watson, dkk., 2014). Dalam kata pengantar buku yang memuat tiga belas bab itu, Watson, dkk. (2014, hlm.3-4) menyebutkan bahwa kajian tentang Ainu sudah terjadi sejak lama, yakni sejak abad ke-19 (tahun 1868) yang diawali dengan kajian antropologi ragawi (physical anthropologi). Dalam perkembangan berikutnya, seperti terungkap dari ketiga belas artikel dalam buku ini, penelitian tentang masyarakat Ainu berkembang ke aspek lain seperti identitas, representasi budaya, budaya materi, gender, regionalisasi, bahasa, hukum, dan tentu saja pariwisata (Watson, dkk., 2014, hlm. 1-24). Walaupun beberapa kajian dalam buku ini memanfaatkan tradisi lisan dalam memahami budaya material Ainu (Ewallen, 2014, hlm. 171-184) dan studi tentang bahasa Ainu
(Refsing, 2014, hlm. 185-199), namun mereka tidak memberikan perhatian khusus tentang tradisi lisan Ainu itu sendiri.

Penelitian Cheung Ainu culture in transition (2003, hlm. 951-959) mengkaji perubahan kebudayaan masyarakat Ainu pasca-ditetapkannya Regulasi Promosi Kebudayaan tahun 1997 banyak membahas kekayaan budaya material dan proses peneguhan identitas etnik Ainu. Sementara di satu pihak Cheung menganalisis banyak perubahan positif pada sikap kebanggaan masyarakat Ainu pada identitasnya, di lain pihak dia bersifat terbuka tentang masa depan masyarakat dan budaya Ainu, dengan mengatakan Ainu memasuki critical period (periode kritis), seperti berikut:

Since the changes that occurred after the 1970s, Ainuculture is now facing anothercritical period. The survival of Ainu culture, whatever form it will take, depends onhow the indigenous rights of Ainu are interpreted at both individual and nationallevels; on how seriously the Japanese government implements the laws protectingindigenous and minority rights and cultural heritage; and on whether Ainu as 'other'remain important to the Japanese in the articulation of their identity (Cheung, 2003, hlm. 959).

Maksudnya adalah sejak perubahan sesudah tahun 1970-an, budaya Ainu menghadapi periode kritis yang lainnya. Pembertahanan budaya Ainu, dalam bentuk apa pun itu terjadi akan tergantung pada bagaimana hak-hak penduduk asli (indigenous) ditafsirkan di tingkat individu dan tingkat nasional; bagaimana seriusnya 
pemerintah Jepang mengimplementasikan hukum proteksi penduduk asli dan hak-hak minoritas dan warisan budaya; dan pada apakah anggapan Ainu sebagai orang lain masih penting dalam artikulasi identitas Jepang. Dalam kesimpulan Cheung ini, perhatian pada tradisi lisan termasuk cerita rakyat mungkin bisa ditafsirkan termasuk perlindungan terhadap warisan budaya (cultural heritage).

Peneliti juga tertarik meneliti tradisi lisan Ainu, seperti yang dilakukan Sarah M. Strong lewat bukunya Ainu Spirits Singing: The Living World of Chiri Yukie's Ainu Shin'yōshū (2011). Buku ini membahas mengenai kumpulan Ainu Shinyōshū sebuah nyanyian sprititual yang ditranskripsikan oleh seorang wanita keturunan Ainu bernama Chiri Yukie (1903-1922). Buku karya Strong ini merupakan literatur penting dalam sejarah penelitian tentang tradisi lisan Ainu, yang merupakan karya kerja sama dengan warga Ainu. Memang, Strong mengkaji tradisi lisan Ainu yang telah direkam oleh warga Ainu sendiri yaitu Chiri Yukie.

Dari penelitian-penelitian yang diuraikan tersebut tampak jelas bahwa tidak ada penelitian khusus tentang cerita rakyat Ainu Jepang yang membahas unsur gastronomi, khususnya cara nenek moyang Ainu mengumpulkan bahan makanan, mengolah, dan cara mereka mengonsumsinya.

\section{HASIL DAN PEMBAHASAN}

\section{Gastronomi dalam Cerita Rakyat Ainu}

Narasi yang mengungkapkan berbagai aspek tentang makanan muncul berulang dalam cerita rakyat Ainu. Ungkapan tentang makanan itu kadang dituangkan dalam deskripsi, narasi, dan kadangjuga dalam dialog dan interaksi antar-tokoh yang terdapat dalam alur cerita. Kisah-kisah cerita rakyat Ainu mengungkapkan informasi tentang makanan dengan berbagai cara, termasuk bagaimana tokoh cerita mencari makanan di hutan, jenis makanan apa yang diperoleh, bagaimana mereka berburu, siapa membantu mereka dalam berburu, daging apa yang dimakan, dan seterusnya. Ada cerita menguraikan cara mendapatkan bahan makanan, cara memasak, dan cara mengawetkan makanan sehingga tetap tersedia ketika musim tidak menumbuhkannya.

Berbagai aspek tentang makanan etnik Ainu tertuang dalam ketujuh cerita rakyat seperti dalam tabel. Cerita rakyat Ainu biasanya dibuka dengan narasi mengenai gambaran tempat tinggal tokoh. Selain itu, cerita juga menuturkan mengenai sumber daya alam atau sumber makanan yang ada di sekitar kehidupan tokoh-tokoh cerita serta cara-cara mereka mendapatkan bahan-bahan makanan tersebut.

Cerita Kin no Kiseru (Pipa Rokok Emas) menyajikan setting hutan dan laut sekaligus tempat masyarakat mencari bahan makanan. Cerita Kin no Kiseru ini mengisahkan seorang laki-laki yang tinggal dekat muara sungai Ishikari, sungai terpanjang di Hokkaido. Saat musim semi, ketika akan mencari makanan di laut (jenis ikan tidak disebutkan), laki-laki ini tidak sengaja melihat seekor burung yang sangat besar dan pada akhir cerita diketahui 
Tabel. Cerita Rakyat Ainu Bertema Gastronomi

Sumber: Hasil Penelitian, 2020

\begin{tabular}{|c|c|c|}
\hline No & Judul Cerita & Aspek Gastronomi \\
\hline 1 & $\begin{array}{l}\text { Kin no Kiseru } \\
\text { (Pipa Rokok Emas) }\end{array}$ & $\begin{array}{l}\text { Kisah seorang laki-laki yang tengah } \\
\text { mencari bahan makanan di hutan } \\
\text { diberikan benda berharga oleh Dewa } \\
\text { Okikurumi, tetapi dia harus memberikan } \\
\text { persembahan (makanan) sebagai } \\
\text { imbalan. }\end{array}$ \\
\hline 2 & $\begin{array}{l}\text { Monoshiri Roujin } \\
\text { (Orang Tua yang Serba Tahu) }\end{array}$ & $\begin{array}{l}\text { Masyarakat berburu untuk memenuhi } \\
\text { kebutuhan hidup. Beruang yang masih } \\
\text { kecil dipelihara sebelum nantinya } \\
\text { dibunuh untuk persembahan kepada } \\
\text { dewa dan dikonsumsi. }\end{array}$ \\
\hline 3 & $\begin{array}{l}\text { Tachi Ki to Totta Sumou } \\
\text { (Bertanding Sumo dengan Pohon } \\
\text { Kokoh) }\end{array}$ & $\begin{array}{l}\text { Masyarakat mengonsumsi daging rusa, } \\
\text { beruang, daun-daun yang dikeringkan } \\
\text { agar awet. }\end{array}$ \\
\hline 4 & $\begin{array}{l}\text { Ekashioppare: Ojiisan ni Fukou o shita } \\
\text { Kodomo no Hanashi } \\
\text { (Cerita Anak yang Tidak } \\
\text { Menghormati Kakeknya) }\end{array}$ & $\begin{array}{l}\text { Memanfaatkan binatang kecil seperti } \\
\text { kelinci, rubah, dan ikan sebagai sumber } \\
\text { makanan. }\end{array}$ \\
\hline 5 & $\begin{array}{l}\text { Iedeshita Inu } \\
\text { (Anjing yang Meninggalkan Rumah) }\end{array}$ & $\begin{array}{l}\text { Kehidupan berburu dengan bantuan } \\
\text { anjing. Berburu sebagai kegiatan mencari } \\
\text { bahan makanan. }\end{array}$ \\
\hline 6 & $\begin{array}{l}\text { Hitotsubu no Satchiporo } \\
\text { (Sebutir Satchiporo) }\end{array}$ & $\begin{array}{l}\text { Memuat narasi cara mengolah } \\
\text { makanan dalam berbagai musim, cara } \\
\text { mengonsumsi satchiporo. }\end{array}$ \\
\hline 7 & $\begin{array}{l}\text { Yotaka ni sareta Kyoudai } \\
\text { (Kakak Beradik yang Berubah } \\
\text { Menjadi Burung Elang Malam) }\end{array}$ & $\begin{array}{l}\text { Dua anak laki-laki yang tidak hormat } \\
\text { dan memberikan makanan yang tidak } \\
\text { baik kepada orang tuanya dan dikutuk } \\
\text { menjadi burung. Juga ada narasi cara } \\
\text { mengolah ikan salmon. }\end{array}$ \\
\hline
\end{tabular}

burung tersebut ternyata Dewa Burung Furi (Burung Raksasa). Perubahan wujud burung furi menjadi manusia tidak sengaja terlihat oleh laki-laki tersebut. Dewa Burung Furi kaget dipergoki lalu meninggalkan semua benda berharga termasuk pipa rokok emas di tempat itu. Sang Burung kembali ke alam dewa. Judul cerita ini, Pipa Rokok Emas, mengacu pada barang milik Sang Burung Furi. Aspek gastronomi cerita ini terletak pada ungkapan sang tokoh cerita yang mengatakan bahwa dia tinggal dekat laut dan gunung, maka dari kedua tempat itulah sumber makanannya diperoleh, seperti bisa disimak dalam kutipan berikut.

…海に近いところなので、食べ物は海 の猟半分、山の猟半分という暮らしをしてい ました (Kayano, 2012, hlm. 23).

(...karena saya tinggal di dekat laut, saya hidup dengan sumber makanan setengah dari perburuan di laut, dan setengah lagi dari hasil perburuan di 
gunung.)

Tinggal di dekat laut dan gunung memang tipikal pola menetap etnik Ainu. Cerita ini melukiskan pengalaman tokoh laki-laki ketika mencari makanan di hutan. Dari kutipan di atas diketahui bahwa tempat tinggal tokoh yang dekat laut dan gunung yang merupakan ciri khas tempat masyarakat Ainu membangun tempat tinggal di tempattempat yang menyediakan banyak sumber makanan. Mereka memilih tempat tinggal di daerah sumber makanan yang bisa mereka peroleh secara berkelanjutan. Dalam buku Walker (2001, hlm. 119) yang berjudul The conquest of Ainu Lands: Ecology and Culture in Japanese Expansion, 1590-1800, Sungai Ishikari disebutkan sebagai tempat bagi Ainu untuk berburu rusa pada musim gugur. Pada musim gugur, rusa-rusa di pegunungan selatan daerah Ishikari menyeberangi Sungai Ishikari menuju ke Shikotsu, karena kalau tidak migrasi, pada saat musim dingin tiba akan turun salju tebal di mana-mana, akibatnya rusa-rusa itu akan sulit mencari makan. Warga Ainu sudah mengetahui siklus migrasi rusa ini sehingga pada saat yang tepat pemburu rusa bersembunyi dengan perahunya, dan begitu melihat rusa-rusa berenang menyeberang, mereka memukul rusa-rusa itu hingga tewas (Walker, 2001, hlm. 119-120) seperti terungkap dalam kutipan berikut.

"As the deer approached the river, Ainu concealedthemselves and their boats behind reed blinds and waited. When thedeer started to swim the river, Ainu overtook them in boats and beatthem to death" (Walker, 2001, hlm. 119-120)
(Ketika rusa mendekati sungai, orang Ainu menyembunyikan dirinya sendiri dan perahunya di balik rimbun daun dan menanti. Ketika rusa mulai berenang di sungai itu, masyarakat Ainu mengejar mereka dengan perahu dan memukulnya sampai mati.)

Selain ikan salmon, daging rusa merupakan makanan penting warga Ainu di masa lalu, zaman hunter-gather, berburu dan meramu (Hudson, 2014, hlm. 126). Perburuan rusa di sungai dilakukan saat binatang ini migrasi mengantisipasi tantangan musim. Ini adalah bukti dekatnya Ainu dengan alam dan isinya sebagai sumber penghidupan. Kajian faktual migrasi binatang dalam siklus musim dan kebiasaan Ainu berburu di sungai Ishikari mendukung narasi dalam cerita rakyat bahwa kehidupan warga Ainu sangat berkaitan dengan alam. Alam menjadi sumber penghidupan etnik Ainu dan pencarian terhadap sumber penghidupan itu dilakukan sesuai dengan siklus musim.

Meskipun alam yang menyediakan banyak bahan makanan, tantangan penduduk Ainu yang tinggal di daerah empat musim juga membuat mereka harus kreatif dalam mengolah makanan. Membaca tandatanda alam dan perilaku binatang serta tumbuh-tumbuhan adalah hal penting, sama pentingnya dengan mengolah bahan makanan sesuai dengan siklus musim.

Berburu merupakan keterampilan hidup yang bergengsi dalam masyarakat Ainu. Dalam cerita rakyat, tokoh cerita yang berburu dilukiskan sebagai orang yang hebat, hero, terutama bagi keluarga karena 
pemburu itu bisa menyiapkan makanan bagi keluarga. Cerita Monoshiri Roujin melukiskan bagaimana seorang istri memuji suaminya sebagai pemburu hebat, seperti dalam kutipan berikut.

夫はたいへん狩りの上手なひとで、い つもたくさんの鹿や熊をとってくるので、わ たしは何をほしいとも、何を食べたいとも思 ったことがありません (Kayano, 2012, hlm. 155).

(Suami saya adalah pemburu yang sangat hebat, ia selalu membawa pulang banyak rusa dan beruang, apa pun yang saya inginkan, dan apa pun yang saya ingin makan saya selalu mendapatkannya.)

Binatang buruan yang dimaksud adalah rusa dan beruang. Pekerjaan berburu berkaitan langsung dengan makan dan makanan. Berburu merupakan cara menyambung hidup dan alam merupakan tempat mencari sumber makanan. Narasi tugas suami berburu dan tugas istri mengolah hasil buruan menjadi makanan di rumah mencerminkan kerja sama harmonis dalam mengolah makanan, artinya kehebatan yang satu tidak akan lengkap, tanpa kehebatan yang lain.

Kehebatan suami berburu muncul berulang dalam beberapa cerita. Cerita lain mengisahkan pengakuan seorang istri terhadap kehebatan suaminya berburu adalah Iedeshita Inu (Anjing yang Meninggalkan Rumah). Selain memuji kehebatan suaminya berburu, sang istri (yang tidak memiliki nama khusus) juga menyampaikan bahwa hasil pekerjaan suaminya membuat kehidupan mereka berkecukupan, seperti terungkap dalam pengakuan istri berikut.
夫は狩りの上手な人なので、いつでも たくさんの鹿をとり、熊をとるので、何不自由 なく暮らしていました(Kayano, 2012, hlm. 177).

(Karena suami saya adalah pemburu hebat, kapan pun bisa mendapatkan rusa dan beruang sehingga kehidupan saya berkecukupan tanpa kekurangan apa pun.) Ungkapan kehidupan saya berkecukupan tanpa kekurangan suatu apa pun menjelaskan kepiawaian berburu dan alam menjadi sumber penghidupan. Budaya hidup berburu sangat tercermin dalam cerita ini dan juga cerita rakyat yang dibahas di atas.

Alam tidak saja menyiapkan rusa dan beruang sebagai binatang buruan, tetapi juga hewan yang lebih kecil seperti kelinci dan rubah. Jika laki-laki tidak lagi kuat untuk berburu rusa dan beruang karena faktor usianya sudah lanjut, mereka akan mencari binatang yang lebih kecil yang tidak sulit untuk ditangkap.

Kisah pengumpulan bahan makanan dan mengolahnya supaya awet untuk dipakai pada musim yang berbeda juga terungkap dalam kisah Tachi Ki to Totta Sumou (Bertanding Sumo dengan Pohon Kokoh). Proses pengolahan itu dilakukan dengan mengeringkannya seperti dalam kutipan berikut ini.

父は鹿や熊をたくさんとり、母は季節ご とに山菜を取っては乾燥させ、その山菜を干 し肉や干し魚といっしょに煮て食べさせてく れます(Kayano, 2012, hlm. 129).

(Ayah saya mendapatkan banyak rusa dan beruang, ibu mengambil sayuran liar di musim yang berbeda dan mengeringkannya, saya diberikan makan 
sayuran liar yang direbus bersama daging atau ikan yang telah dikeringkan.)

Cerita rakyat ini melukiskan tokoh lakilaki dan perempuan mencari bahan makanan. Tokoh ayah pergi berburu, sedangkan tokoh ibu memetik sayuran liar. Dalam cerita ini juga dituturkan bagaimana penduduk Ainu mengenal cara mengawetkan makanan dengan cara dikeringkan, baik daging maupun ikan.

Cerita Ekashioppare: Ojiisan ni Fukou o shita Kodomo no Hanashi (Cerita Anak yang Tidak Menghormati Kakeknya) melukiskan mengenai seorang kakek yang sudah terlalu tua untuk berburu dari sudut pandang tokoh utama cerita seorang pemuda, seperti dalam kutipan berikut.

おじいさんは、あまりにも年を取ってい るので、たくさんいる熊や鹿をとることができ ません。うさぎやきつねのように小さい獲物 をとって、その肉や、魚のおいしい脂身のほう をわたしに多く食べさせてくれます(Kayano， 2012, hlm. 101).

(Kakek saya sudah terlalu tua untuk bisa memburu beruang dan rusa yang banyak tersedia. Kakek memberi saya makan daging binatang buruan yang kecil seperti kelinci, rubah, dan juga bagian daging ikan yang enak.)

Pada kebanyakan kisah, laki-laki yang pandai berburu akan menjamin keluarganya agar tidak sampaikekurangan makanan seperti pada cerita Monoshiri Roujin dan Iedeshita Inu. Binatang yang paling sering menjadi buruan adalah beruang dan rusa. Selain itu, ada pula mereka yang berburu binatang kecil, misalnya kelinci atau pun rubah serta ikan. Ceritacerita yang ada menunjukkan etnik Ainu dekat dengan alam dan alam menjadi sumber penghidupan.

Hampir tidak ada cerita yang melukiskan sumber makanan etnik Ainu di luar tangkapan binatang, ikan, petikan sayur, atau sumber di luar alam. Secara tidak langsung, cerita yang bertema atau subtema alam sebagai sumber penghidupan, juga memberikan etnik Ainu pengetahuan tradisional untuk hidup dari alam, dan cara mengumpulkan dan mengolah makanan yang bersumber dari alam.

Cerita rakyat Ainu banyak mengandung pengetahuan tradisional yang dipraktikkan manusia dalam menyambung hidupnya, misalnya dalam mencari sumber makanan dan mengolah berbagai jenis makanan sehingga bisa disimpan untuk dikonsumsi pada musim-musim yang berbeda.

Proses pengolahan makanan yang muncul berulang misalnya olahan telur salmon, dango, dan citatap. Pengetahuan atau keterampilan tradisional itu disuratkan secara tidak langsung, dalam arti dia melekat sebagai hal yang dilaksanakan oleh tokoh cerita sehingga kehadirannya tidak membuat alur atau narasi cerita berubah menjadi teks eksposisi. Dengan kata lain, meskipun mengandung unsur pengetahuan atau keterampilan tradisional, cerita tetap merupakan kisah narasi yang menarik.

Cerita Hitotsubu no Satchiporo, mengisahkan tentang seorang perempuan yang tinggal bersama kedua orang tuanya yang sudah renta. Diceritakan bagaimana mereka, khususnya protagonis perempuan, memanfaatkan hasil hutan sebagai makanan pada keempat musim yang berbeda di 
Jepang: musim semi, panas, gugur, dan dingin. Siklus musim memaksa manusia untuk membangun pengetahuan mengenai cara-cara mengawetkan makanan sehingga mereka bisa bertahan dan dikonsumsi ketika alam tidak menyediakan karena pergantian musim. Hal ini tercermin dalam cerita Hitotsubu no Satchiporo khususnya mengenai bagaimana hasil buruan atau sayuran liar yang dikumpulkan dan diawetkan agar bisa menjadi sumber makanan selama satu tahun, seperti terungkap dari ungkapan protagonis cerita berikut.

季節ごとに食べ物を集めては、だい じに保存して、ほそぼそと暮らしていました (Kayano, 2012, hlm. 50).

(Kamihidup dengan sangat sederhana dengan mengumpulkan makanan setiap musim dan mengawetkannya sebaik mungkin.)

Proses pengolahan bahan makanan berupa sayur dalam cerita sama, juga bisa disimak dalam kutipan berikut.

わたしは、女でできること、春は山菜を とってはそれを食べ、あるいは冬食べる分 は、乾かして保存して、ふたりの年老いた親を 養っていました (Kayano, 2012, hlm. 49).

(Saya melakukan pekerjaan yang dapat dikerjakan perempuan, ketika musim semi, saya memakan daun liar yang saya petik, atau saat musim dingin, daun tersebut saya keringkan dan si simpan, dan saya berikan kepada kedua orang tua saya.)

Selain melukiskan cara tokoh memetik bahan sayuran di semak-belukar, cerita juga melukiskan bagaimana dia mencari bahan makanan lain berupa umbi ubayuri pada musim panas untuk diolah menjadi bahan makanan pada musim dingin. Kutipan berikut menjelaskan proses pencarian bahan makanan dan pengolahannya yang berkait erat dengan siklus musim, sebuah pengetahuan atau keterampilan hidup dalam mencari bahan makanan di alam dan mengolahnya untuk konsumsi.

夏になると、うばゆりの根を掘ってきて はきれいに水で洗いうすでつきくだいて、澱 粉を取った残りの粕は、青草に包んで発酵さ せます。発酵したものは、直径一五センチメー トルぐらいの大きな団子につくつて干してお き、長い冬の食料にしました。寒い冬がきて 団子を食べるときは、団子を水につけてやわ らかくして、うすに入れてつき、もう一度団子 につくつて煮て食べます。

…見えかくれしながらしばらく行くと、 一軒の家がありました。家の外には、おいし いそうな干し肉や、干し魚がたくさんさおに かけて干してあります(Kayano, 2012, hlm. $49-50)$.

(Ketikamusimpanastiba, umbiubayuri yang telah saya gali, saya bersihkan dengan air, dihancurkan sampai tipis, kemudian setelah menjadi tepung, dibungkus dengan rumput hijau dan difermentasikan. Makanan yang difermentasikan dibuat menjadi dango berukuran besar yang dikeringkan dengan diameter $15 \mathrm{~cm}$ dan menjadi bahan makanan selama musim dingin yang panjang. Ketika memakan dango saat musim dingin tiba, lembutkan dango dengan memasukkan air, masukkan tepung, sekali lagi dango dibuat dan direbus lalu dimakan. 
...kemudian saya melihat sebuah rumah. Di luar rumah tersebut, ada banyak daging dan ikan yang dikeringkan dan terlihat enak.)

Dari kutipan tersebut diketahui bagaimana seorang gadis bertahan hidup dengan mengolah hasil hutan berupa daundaunan. Hal ini dilakukan karena sebagai perempuan ia tidak memiliki kemampuan berburu. Cerita ini mempertegas nilai sosial budaya Ainu khususnya tentang perempuan bertugas mengolah makanan di rumah atau kalau pun mereka harus mencari ke alam bebas, itu dilakukan untuk pencarian yang ringan. Tugas berburu yang memerlukan tenaga dan keberanian dilakukan laki-laki dewasa. Dalam pembagian kerja secara seksual di rumah tangga ini tidak secara serta merta berarti bahwa perempuan sepenuhnya tergantung pada laki-laki, atau sebaliknya laki-laki bergantung pada perempuan. Mereka menunjukkan pembagian kerja yang saling melengkapi atau juga sesuai dengan situasi dan kondisi. Artinya, ketika lakilaki atau orang tua di rumah tangga sudah tidak mampu melakukan pekerjaan berburu sehingga tidak bisa menyediakan bahan makanan untuk keluarga, tugas mencari makanan bisa dilakukan oleh perempuan.

Dalam artikelnya Regional Variations in Ainu Culture, Ohnuki-Tierney (1976) menyampaikan betapa pentingnya bahan makanan dari tumbuhan, terutama bagi keluarga-keluarga yang tidak mempunyai laki-laki yang mampu berburu. Pentingnya makanan dari tumbuhan (plant food) dan absennya laki-laki berburu dalam keluarga, ditegaskan Ohnuki-Tierney (1976, hlm. 305) seperti berikut.

Plant food was certainly not insignificant for them, as they expended much effort during the summer drying and storing edible plants for winter use. Among them, plant foods comprised the major portion of the diet for families which did not have able-bodied men to hunt and fish for them. (Ohnuki-Tierney, 1976, hlm. 305)

(Makanan dari tumbuhan tentu tidak sepele bagi mereka karena mereka menghabiskan banyak usaha selama musim panas mengeringkan dan menyimpan tanaman yang dapat dimakan untuk digunakan di musim dingin. Di antara mereka, makanan nabati terdiri atas porsi utama diet untuk keluarga yang tidak memiliki laki-laki berbadan sehat untuk berburu dan menangkap ikan untuk mereka.)

Tokoh perempuan dalam cerita Hitotsubu no Satchiporo menuturkan bagaimana dia memetik daun-daun dan umbi-umbian yang dapat dijadikan sebagai sumber makanan sebanyak-banyaknya pada musim gugur.

Latar waktu musim gugur penting ditekankan di sini tidak saja karena menentukan alur cerita, tetapi juga menegaskan bagaimana alam memberikan pelajaran bagi manusia untuk beradaptasi, untuk menciptakan pengetahuan tradisional yang bisa dipraktikkan dan dijadikan tradisi sehingga terasa sebagai sebuah kebiasaan alami. Pentingnya tokoh perempuan mencari bahan makanan pada saat musim gugur karena dedaunan tersebut juga akan dijadikan sumber makanan ketika musim dingin. 
Perlu diketahui bahwa musim salju di Pulau Hokkaido yang merupakan pulau paling utara Jepang memiliki suhu yang paling dingin, jika dibandingkan dengan dengan daerah di Jepang lainnya. Pada suhu yang ekstrim itu, ketika salju menyelimuti sebagian besar semak belukar dan ladang-ladang, tidak memungkinkan bagi masyarakat untuk mencari makanan ke luar rumah. Musim gugur berarti meramu, musim dingin berarti menikmati stok makanan yang dikumpulkan dalam musim gugur.

Setiap pergantian musim memberikan cara berbeda bagi masyarakat Ainu untuk mengolah dan mengonsumsi makanan. Berbeda dengan ketika musim gugur dan dingin, pada musim panas tokoh perempuan mencari bahan-bahan untuk membuat kue dango, kue ini pun disimpan agar dapat dinikmati pada musim dingin yang panjang. Pada cerita ini umbi yang disebutkan adalah umbi yang bernama ubayuri. Terdapat istilah mokiuta, mendekati waktu untuk memanen ubayuri, saat ini penduduk Ainu mulai mempersiapkan diri untuk panen. Ada pula yang disebut shikiuta, waktu untuk memanen umbi ubayuri. Saat ini biasanya para wanita Ainu memasuki pegunungan berkelompok untuk memanennya. Umbi ubayuri bagi penduduk Ainu adalah sumber makanan penting yang mengandung pati (Hata, 2017). Pengetahuan tradisional mengenai proses membuat kudapan dango dituturkan mulai dari tahap mencari bahannya yaitu umbi, mengolah, melakukan fermentasi, mengolah dijelaskan agak detail sampai ukuran diameter kue $15 \mathrm{~cm}$, serta cara menghangatkan saat dikonsumsi pada musim dingin, yaitu dengan mengisi air, memasukkan tepung, kemudian menghangatkannya.

Selain cara membuat dan mengonsumsi dango, cerita Hitotsubu no Satchiporo juga menyajikan cara masyarakat Ainu Jepang mengolah hewan hasil buruannya. Informasi cara mengolah hewan hasil buruan dibungkus dengan narasi yang dimulai dengan ketika tokoh perempuan dalam cerita ini mendatangi rumah laki-laki yang sudah dijodohkan oleh orang tuanya. Di rumah calon suaminya itu tokoh perempuan melihat daging dan ikan yang telah diasapkan atau diawetkan dengan cara digantung di atap rumah. Cara mengawetkan ikan secara tradisional ini menunjukkan bahwa masyarakat Ainu Jepang sejak dulu telah mengetahui bagaimana memanfaatkan hasil alam untuk waktu yang lebih lama. Dedaunan atau bahan makanan yang sama bisa diolah dan dimakan hingga empat musim. Begitu pula hewan tangkapan mereka awetkan sehingga tidak ada bahan makanan yang terbuang, tidak juga ada istilah kelaparan ketika musim berburu tidak dimungkinkan karena cuaca ekstrim.

Masih pada cerita yang sama, Hitotsubu no Satchiporo, dilukiskan ketika laki-laki yang dikunjungi dua orang perempuan yang wajahnya serupa itu ingin membuktikan mana gadis yang sesungguhnya adalah manusia dan mana yang siluman. Untuk membuktikan itu, tokoh laki-laki menawarkan kedua wanita itu satchiporo, telur ikan salmon yang telah dikeringkan. Perempuan pertama memakannya satu per satu dan menikmatinya dengan perlahan, sedangkan perempuan 
kedua memakannya sekaligus sehingga diketahui bahwa wanita yang memasukkan seluruh telur ke dalam mulutnya sekaligus adalah siluman rubah dan bukan manusia. Kisah ini mengajarkan bagaimana tata cara untuk memakan satchiporo yang baik.

Dalam cerita dituturkan bahwa perempuan sejati ini sudah sejak kecil diajarkan cara mengonsumsi satchiporo dengan baik, dan pengetahuan tradisional itu diajarkan oleh ayahnya, seperti terungkap dalam kutipan berikut.

わたしは子どものころ、父がつくったサ ッチポロをたべたことがあり、サッチポロを 食べるときは、ひとつぶずつ口に入れて、ゆっ くりかむということを父に教えられていました (Kayano, 2012, hlm. 55).

(Ketika saya masih kecil, saya pernah memakan satchiporo (telur ikan salmon yang dikeringkan) buatan ayah saya, ayah saya mengajarkan bahwa cara memakan satchiporo adalah dengan memasukkannya satu per satu ke mulut dan mengunyahnya dengan perlahan.)

Cerita ini menarik karena mengandung tata cara mengonsumsi makanan. Cara makan atau dalam arti luas bisa dikenal sebagai etiket makan merupakan refleksi budaya. Identitas sebuah masyarakat terkadang ditentukan oleh cara makannya, misalnya Cina, Jepang, dan Korea dikenal makan memakai sumpit.

Satu lagi pengetahuan tata boga Ainu yang dinarasikan dalam cerita Ainu adalah cara membuat citatap, makanan khas Ainu. Makanan yang berbahan baku ikan salmon ini diselipkan dalam cerita Yotaka ni sareta Kyoudai (Kakak Beradik yang Berubah Menjadi Burung
Elang Malam). Proses pembuatan citatap sudah dimulai dari cara memilih bahan dari bagian salmon dan cara memotongnya, serta bumbu lain yang diperlukan. Kutipan berikut yang dituturkan narator cerita menjelaskan proses dan cara serta makna citatap.

むすこたちは、川にたくさんいる鮭をと つてきては、氷頭のところ(頭の軟骨)で、チタ タプというぬたをつくります。イタタニという 肉切り台の上で、鮭の水頭を切りきざむと、 ロロロッロロロッという音がして $\cdots$ (Kayano, 2012, hlm. 38).

(Anak-anak laki-laki itu membuat salad dengan bumbu miso yang disebut citatap dari ikan salmon yang banyak ada di sungai, dengan mengambil bagian hizu (tulang rawan kepala). Saat memotong bagian tulang rawan kepala salmon di tempat memotong daging yang disebut itatani, terdengarlah suara rororot )

Ada empat istilah khusus dalam kutipan ini yang berkaitan dengan citatap, yaitu hizu (tulang rawan bagian kepala salmon), miso (bumbu), itatani (takalan yang digunakan mencincang daging salmon), dan onomatope rororot rororot (suara gergaji memotong tulang rawan kepala salmon).

Sebagai makanan khas Ainu, citatap memang wajar menjadi inspirasi cerita rakyat, melalui cerita rakyat itulah popularitas citatap dan cara membuatnya dituturkan, artinya juga diabadikan lintas waktu. Dengan kata lain, cerita rakyat merupakan dokumen budaya, sesuai dengan prinsip antropologi sastra.

Pada cerita Yotaka ni sareta Kyoudai penyimak cerita rakyat mendapatkan informasi mengenai cara membuat dan 
makna bunyi rororot rororot yang dihasilkan selama proses pembuatan. Dua tokoh kakak beradik mengambil ikan salmon di sungai, dagingnya dipisahkan dan diambil hanya bagian hizu (daging pada tulang rawan di kepala). Citatap ini sendiri berasal dari bahasa Ainu yang berarti makanan yang dipukulpukul (Kurashino, 2018). Pembuatannya pun dengan cara mencincang daging berulangkali di alas yang bernama itatani. Suara yang dihasilkan ketika proses pembuatan pada data digambarkan sebagai suara rororot rororot. Suara rororot rororot seperti yang dihasilkan tersebut, pada akhir cerita akan menjadi suara yang dikeluarkan kedua anak laki-laki ketika telah dikutuk menjadi burung karena tidak memberikan makanan dengan baik kepada orang tuanya. Ajaran moral juga sangat kental pada cerita ini, mengingatkan agar anak-anak selalu menjaga orang tua seperti orang tua menjaga anak-anaknya semasa kecil. Dalam cerita ini, substansi dan pesan cerita tentang nilai moral dan ihwal memasak berpadu dengan kuat.

\section{PENUTUP}

Artikel ini menganalisis aspek gastronomi cerita rakyat Ainu Jepang. Berdasarkan analisis atas bagaimana ihwal makanan dinarasikan, atau dituturkan di dalam cerita rakyat Ainu Jepang, berikut ini dapat ditarik dua simpulan.

Pertama, cerita rakyat Ainu Jepang yang bertemakan gastronomi memiliki beragam bentuk dalam menarasikan makanan. Bentuk narasi tersebut bisa dibedakan menjadi dua yaitu (a) cerita yang menarasikan caracara mengumpulkan bahan makanan, seperti berburu dan memetik sayur di semak-belukar atau kebun; (b) cerita yang menguraikan secara rinci cara mengolah dan mengonsumsi makanan. Kedua bentuk narasi itu merefleksikan sebagian dari aspek budaya Ainu sebagai masyarakat yang berburu dan meramu.

Kedua, cerita rakyat Ainu Jepang yang bertema atau bersubtema gastronomi menyelipkan pesan moral dan dinilai kepercayaan dalam kehidupan sosial masyarakat. Bagi masyarakat Ainu, masakan citatap merupakan lauk yang digemari masyarakat secara turun-temurun. Dalam cerita rakyat Ainu, cerita tentang citatap digunakan untuk menyampaikan pesan moral mengenai pentingnya anak-anak menunjukkan rasa hormat kepada orang tua dan sopan santun dalam mengkonsumsi makanan.

Dari simpulan itu jelas terbayang bahwa cerita rakyat Ainu Jepang yang mengambil tema utama makanan bisa dijadikan dasar untuk merekonstruksi resep masakan dengan segala perubahannya lintas waktu. Artikel ini belum sampai pada rekonstruksi resep, sebuah topik kajian yang penting dilaksanakan dalam tahap berikutnya dan memerlukan keterampilan gastronomi khusus memasak sehingga konstruksi resep bisa lebih akurat dan teruji. 


\section{Ucapan Terima Kasih}

Artikel ini berdasarkan hasil penelitian yang didanai oleh Lembaga Penelitian dan Pengabdian pada Masyarakat Universitas Udayana dalam skema Penelitian Unggulan Udayana, dengan kontrak nomor: 551-90/ UN14.4.A/LT/2019. Penulis berterima kasih kepada Rektor Unud, Ketua LPPM Unud, Dekan Fakultas Ilmu Budaya Unud atas dukungan dan bimbingannya.

\section{Daftar Pustaka}

Barrère, C., Bonnard, Q., \& Chossat, V. (2012). "Food, gastronomy and cultural commons". In E. Bertacchini, G. Bravo, M. Marrelli andW. Santagata (Eds.), Cultural commons: A new perspective on the production and evolution of cultures (hlm. 129-150). Cheltenham, UK: Edward Elgar.

Bestor, Theodore C. and Victoria Lyon Besto. 2011. Cuisine and Identity in Contemporary Japan. Education About Asia Volume, 16 (3), 13-18.

Bramantio, Bramantio. 2013. Sastra Dan Kuliner: Evolusi Gastronomi Ke Gastrosofi Dalam Tiga Cerpen Indonesia, Jentera, 2 (1), 42-55.

Cheung, S.C.H. 2003. Ainu Culture in Transition. Futures 35, 951-959.

Danandjaja, Djames. 1995. A Comparative Study of Japanese and Indonesian Folklores, Southeast Asian Studies, 33 (3), 202-214.

Danandjaja, James. 1986. Folklor Indonesia, Ilmu Gosip, Dongeng, dan lain-lain. Jakarta: Pustaka Utama Grafiti.

Endraswara, Suwardi. 2018. Metode Penelitian Gastronomi Sastra. Yogyakarta: Textium.

HATA. 2017. "Living Together with Forest." http://hokkaido-adventuretravel.com/ program/program-title-007/.

Hayashi, Yoshishige. 1970. Ainu Food. Hokudai Economic Papers, 2, 1-15.

Hjalager, Anne-Mette dan Greg Richards (eds.) 2002. Tourism and Gastronomy. London: Routedge.

Kayano, Shigeru. 2012. Ainu Mukashi Banashi: Hito Tsubu no Satchiporo. Tokyo: Heibonsha.
Kayano, Shigeru. 2004. The Ainu: A Story of Japan's Original People. Tokyo: Tuttle Publishing.

Kayano, Shigeru. 2005. Kayano Shigeru: Ainu no Sato Nibutani ni Ikite. Tokyo: Nihontoshosentaa.

Kurashino. 2018. "Ainu Ryouri to wa? Sono Skoku Bunka to Tokyo de Ainu Ryouri ga Taberareru Omise o Goshoukai!" https://kurashi-no.jp/I0016230.

Lewallen, Ann-Elise. 2014. The Gender of Cloth: Ainu Woman and Cultural Revitalization dalam Hudson, Mark J., Ann-Elise Lewallen, dan Mark K. Watson (ed.) Beyond Ainu Studies. Honolulu: University of Hawai'I Press, hlm. $171-184$.

Molina, María de Miguel, Blanca de Miguel Molina, Virginia Santamarina Campos dan María del Val Segarra Oña. (2016). Intangible Heritage and Gastronomy: The Impact of UNESCO Gastronomy Elements. Journal of Culinary Science \& Technology, 14 (4), 293-310.

Pialang, Yasraf Amir dan Rully Darmawan. 2014. Kreativitas Desain Kuliner dan Sistem Inovasi Lokal. Panggung 24 (3), 285-294.

Refsing, Kirsten. 2014. From Collecting Words to Writing Grammars: A Brief History of Ainu Linguistics dalam Hudson, Mark J., Ann-Elise Lewallen, dan Mark K. Watson (ed.) Beyond Ainu Studies. Honolulu: University of Hawai'I Press, hlm. 185-199.

Setiawan, Deni, Timbul Haryono, dan M. Agus Burhan. 2014. Prinsip Estetika Pakaian Cosplay Yogyakarta: Fantasi dan Ekspresi Desain Masa Kini. Panggung, 24 (1), 39-48.

Strong, Sarah M. 2009. The Most Revered of Foxes: Knowledge of Animals and Animal Power in an Ainu KamuiYukar. Asian Ethnology, 68 (1), 27-54.

Strong, Sarah M. 2011. Ainu Spirits Singing: The Living World of Chiri Yukie's Ainu Shin'yushu. Honolulu: University of Hawai'i Press.

Vecco, M. (2010). "A definition of cultural heritage: From the tangible to the intangible". Journal of Cultural 
Heritage, 11 (3), 321-324.

Watson, Mark K., Ann-Elize Lewallen, dan Mark J. Hudson. (2014). "Beyond Ainu Studies An Introduction" dalam Hudson, Mark J, Ann-Elise Lewallen, dan Mark K. Watson (ed.) Beyond Ainu Studies. Honolulu: University of Hawai'I Press, hlm. 1-24. 